\title{
Katyon Değişim Reçinesi Kullanarak Sulu Çözeltilerden Amonyum Giderimi
}

\author{
Nejdet Değermenci ${ }^{1 *}$ \\ 1* Kastamonu Üniversitesi, Mühendislik ve Mimarlık Fakültesi, Çevre Mühendisliği Bölümü, Kastamonu, Türkiye, (ORCID: 0000-0003-3135-1471), \\ degermenci@kastamonu.edu.tr
}

(Illk Geliş Tarihi 22 Ocak 2021 ve Kabul Tarihi 28 Mart 2021)

(DOI: 10.31590/ejosat.866673)

ATIF/REFERENCE: Değermenci, N. (2021). Katyon Değişim Reçinesi Kullanarak Sulu Çözeltilerden Amonyum Giderimi. Avrupa Bilim ve Teknoloji Dergisi, (23), 272-279.

$\ddot{O} \mathbf{z}$

Amonyum, su kütlelerinin ötrofikasyonundan sorumlu temel faktörlerden biridir. Amonyum giderim etkinliği üzerindeki potansiyel kullanımını araştırmak amacıyla Purolite SSTC60 iyon değiştirici reçine kullanılmışır. İyon değiştirici reçine dozajı, başlangıç çözelti pH'1, sıcaklık, karıştırma hızı ve başlangıç amonyum konsantrasyonu gibi iyon değişimini etkileyen önemli parametrelerin amonyum giderimi üzerine etkisi araştırılmıştır. En yüksek amonyum giderimi pH 7 değerinde sağlanmıştır. Reçine dozajı, karıştırma hızı ve sıcaklık artışı ile amonyum giderim hızlarının arttığı belirlenmiştir. $20^{\circ} \mathrm{C}^{\prime}$ den daha yüksek sıcaklıkların ve karıştırma hızının denge anında ki amonyum giderim verimleri üzerine çok fazla bir etkisi olmadığı belirlenmiştir. Başlangıç amonyum konsantrasyonlarının artı̧ı ile giderim verimlerinin azaldığı gözlenmiştir. Amonyum iyonlarının gideriminde en uygun kinetik modeli belirlemek üzere yalancı birinci derece ve yalancı ikinci derece kinetik denklemler lineer olmayan yöntem kullanılarak analiz edilmiş ve yalancı birinci derece kinetik model ile uyumlu olduğu görülmüştür. Son olarak, deneysel verilerin Langmuir ve Freundlich izoterm modellerinin doğrusal olmayan formları kullanılarak yapılan değerlendirme de adsorpsiyon verilerinin Langmiur izoterm modelinden ziyade Freundlich izoterm modeline uyduğu belirlenmiştir.

Anahtar Kelimeler: Amonyum giderimi, İyon değişimi, Ötrofikasyon, Kinetik, Purolite SSTC60.

\section{Ammonium Removal from Aqueous Solutions Using Cation Exchange Resin}

\begin{abstract}
Ammonium is one of the main factors responsible for eutrophication of water bodies. Purolite SSTC60 ion exchange resin was used to investigate its potential use on ammonium removal efficiency. The effects of important parameters affecting ion exchange such as ion exchange resin dosage, initial solution $\mathrm{pH}$, temperature, mixing speed and initial ammonium concentration on ammonium removal were investigated. The highest ammonium removal was achieved at $\mathrm{pH} 7$. It was determined that ammonium removal rates increased with resin dosage, mixing speed and temperature increase. It has been determined that temperatures higher than $20^{\circ} \mathrm{C}$ and mixing speed do not have a significant effect on ammonium removal efficiencies at equilibrium. It was observed that removal efficiencies decreased with increasing initial ammonium concentrations. Pseudo-first order and pseudo-second order kinetic equations were analyzed using nonlinear method to determine the most appropriate kinetic model for ammonium ion removal and found to be compatible with the pseudo-first order kinetic model. Finally, the evaluation of experimental data using nonlinear forms of Langmuir and Freundlich isotherm models determined that the adsorption data fit the Freundlich isotherm model rather than the Langmiur isotherm model.
\end{abstract}

Keywords: Ammonium removal, Ion exchange, Eutrophication, Kinetic, Purolite SSTC60.

\footnotetext{
*Sorumlu Yazar: degermenci@ kastamonu.edu.tr
} 


\section{Giriş}

Amonyum, su ve atıksuların arıtılmasında önemli parametrelerden biridir. Sulu çözeltideki toplam amonyak, bağıl konsantrasyonları $\mathrm{pH}$ ve sıcaklığa bağlı olan, amonyum iyonu $\left(\mathrm{NH}_{4}{ }^{+}\right)$ve serbest amonyak $\left(\mathrm{NH}_{3}\right)$ olmak üzere iki formdan oluşur (Bonmatí ve Flotats, 2003; Körner ve ark., 2001). Doğal sularda baskın olan tür amonyum iyonudur. İçme suyu kaynağ olarak hizmet eden belirli yüzey sularındaki $\mathrm{NH}_{4}{ }^{+}$ konsantrasyonu izin verilen seviyeden daha yüksektir. Çünkü büyük miktarda kentsel, tarımsal veya endüstriyel atık sular mevcut su kaynaklarına deşarj edilmektedir. Alıcı su ortamlarına deşarj edilen amonyum iyonu, yüzeysel su rezervuarlarında ötrofikasyona, çözünmüş oksijenin azalmasına, sucul yaşam için toksisiteye ve toprak malzemelerinde artan korozyon h1z1 gibi zararlı etkilere neden olabilir (Alshameri ve ark., 2014; Saltali ve ark., 2007). Ayrıca, içme suyunda bulunan amonyum, insan sinir sistemine zarar verebilecek ve suyun tadının ve kokusunun bozulmasına sebep olabilecek dezenfeksiyon yan ürünleri oluşturmak üzere klor ile reaksiyona girmektedir. $\mathrm{Bu}$ nedenlerden dolayı amonyum iyonunun deşarjını kısıtlayan yasa ve yönetmelikler uygulamaya alınmıştır ve amonyağı sudan giderebilmek ya da geri kazanabilmek için birçok yöntem geliştirilmiştir. $\mathrm{NH}_{4}{ }^{+}$giderimi için kullanılan yöntemlerden bazıları biyolojik arıtım (nitrifikasyon ve denitrifikasyon), hava sıyırma, foto-katalitik bozunma, ters ozmos, kimyasal çöktürme, elektro-kimyasal oksidasyon süperkritik su oksidasyonu ve iyon değiştirme sayılabilir (Carrera ve ark., 2003; Değermenci ve ark., 2012; Taşdemir ve ark., 2020; Bahmani ve ark., 2020; Mondor ve ark., 2008; Uludag-Demirer ve ark., 2005; Chung ve ark., 2020; Bermejo ve ark., 2008). İyon değiştirme işlemi kullanılarak kirlenmiş doğal sulardan ve atık sulardan çok çeşitli kimyasallar etkili bir şekilde giderilebilir. Örneğin, anyon değişim reçineleri kullanılarak nitrat, nitrit, fosfat, uranyum ve fenol gibi anyonik maddelerin giderimi yapılmıştır (Aşçi ve ark., 2018; Awual ve Jyo, 2011; Caetano ve ark., 2009; Kalaruban ve ark., 2016; Wen ve ark., 2019). Ayrıca katyon değişim reçinesi kullanılarak amonyum, demir, bakır, çinko ve krom giderimleri test edilmiştir (Bashir ve ark., 2010; Lin ve Juang, 2007; VíctorOrtega ve ark., 2016).

İyon değişimi, bir elektron kaybetmiş veya kazanmış ve böylece çözeltiden elektrik yükü almış bir iyon, atom veya molekülün, sabit bir katı parçacığa bağlı benzer yüklü bir iyonla yer değiştirildiği, tersine çevrilebilir bir kimyasal reaksiyondur. İyon değişim reçineleri, değişim için pozitif yüklü mobil iyonları olan katyon değiştiriciler ve değiştirilebilir iyonları negatif yüklü anyon değiştiriciler olarak sınıflandırılabilir (Hazwani-Oslan ve ark., 2017; Paul Chen ve ark., 2002). Sentetik iyon değiştiriciler iyi mekanik mukavemet, farklı yapılar ve hılı rejenerasyon kapasitesine sahip olmaları nedeniyle amonyum giderimi için kullanılabilir (Ding ve Sartaj, 2016). İyon değiştirme yöntemi şok yüklemeleri kaldırabilme kabiliyetine sahiptir ve geniş bir sıcaklık aralığında çalışabilir (Nur ve ark., 2015). Dahası, iyon değiştirme işlemi sadece amonyum giderimi için değil, aynı zamanda amonyum geri kazanımı için de kullanılabilir. Ancak bu sentetik polimerik malzemelerin üretim maliyetleri ve su içerisinde var olan diğer katyonların etkisi yaygın uygulamalarını sınırlandırmaktadır (Cheng ve ark., 2018). Bu nedenle ticari olarak satışı yapılan reçinelerin giderim performanslarını belirlemek amacıyla laboratuvar çalışmaları yapılmaktadır.
Bu çalışmanın amacı, Purolite SSTC60 katyon değişim reçinesi kullanarak sulu çözeltilerden amonyum giderimini araştırmaktır. Kesikli işletilen bir reaktörde çalışmalar yapılarak başlangıç $\mathrm{pH}$ değeri, reçine dozajı, karıştırma hızı, başlangıç amonyum konsantrasyonu ve sicaklığın amonyum giderimine olan etkileri araştırılmıştır. Amonyum gideriminin yalancı birinci derece ve yalancı ikinci derece kinetik modellere uygunluğu incelenmiştir. Ayrıca elde edilen deneysel verilerin Langmuir ve Freundlich adsorpsiyon izoterm modelleri ile uyumluluğu da araştırılmıştır.

\section{Materyal ve Metot}

Çalışmada iyon değiştirici reçine olarak kuvvetli bir katyon değişim reçinesi olan Purolite SSTC60 kullanılmıştır. Kullanılan reçineye ait özellikler ise Tablo 1'de verilmiştir. Amonyum iyonları içeren çözeltilerin hazırlanmasında $\mathrm{NH}_{4} \mathrm{Cl}$ kullanılmıştır. Çözeltiler hazırlanırken saf su kullanılmış olup çözeltilerin $\mathrm{pH}$ değerlerinin ayarlanmasında seyreltik $\mathrm{HCl}$ ve $\mathrm{NaOH}$ çözeltilerinden yararlanılmıştır. pH ölçümlerinde WTW MultiLine Multi 3620 IDS taşınabilir çoklu parametre ölçer kullanılmıştır.

Tablo 1. SSTC60 katyon değişim reçinesinin özellikleri

\begin{tabular}{ll}
\hline Özellik & Açıklama \\
\hline Polimer yapısı & $\begin{array}{l}\text { Divinilbenzen ile çapraz } \\
\text { bağlanmış jel polistiren }\end{array}$ \\
Fonksiyonel grup & Sülfonik asit \\
Görünüm & Küresel boncuk \\
İyonik yükü & $\mathrm{Na}^{+}$ \\
Kapasite & $3.80 \mathrm{eq} / \mathrm{kg} \mathrm{Na}^{+}$ \\
Partikül büyüklüğü & $0.3-1.2 \mathrm{~mm}$ \\
Maksimum çalışma sıcaklığı & $60^{\circ} \mathrm{C}$ \\
Su tutma kapasitesi & $\% 38-46$ \\
\hline
\end{tabular}

Deneylerde kullanılan ceketli reaktörde ki çözelti hacmi 500 mL olup karıştırmayı sağlamak amacıyla MTOPS MS-3020D model mekanik karıştırıcı kullanılmıştır. Reaktördeki sıcaklık ise LABO C200-H13 1sitmalı soğutmalı sirkülatör kullanılarak istenilen sicaklıkta sabit tutulmuştur. Her bir deneyde zamana bağlı olarak alınan numunelerde amonyum konsantrasyonları spektrofotometre (Hach Lange DR6000) ile Nessler metodu kullanılarak belirlenmiştir. Amonyum giderim verimi (R), zamana bağlı iyon değişim kapasitesi ve denge anında iyon değişim kapasiteleri ise Eşitlik 1 - 3 kullanılarak hesaplamıştır:

$$
\begin{aligned}
& R(\%)=\frac{C_{0}-C_{t}}{C_{0}} \times 100 \\
& q_{t}=\frac{\left(C_{0}-C_{t}\right) \times V}{m} \\
& q_{e}=\frac{\left(C_{0}-C_{e}\right) \times V}{m}
\end{aligned}
$$

burada $\mathrm{C}_{0}$, başlangiç amonyum konsantrasyonunu (mg/L), $\mathrm{C}_{\mathrm{t}}, \mathrm{t}$ zamanındaki amonyum konsantrasyonunu (mg/L), $\mathrm{C}_{\mathrm{e}}$, denge anındaki amonyum konsantrasyonunu $(\mathrm{mg} / \mathrm{L}), \mathrm{V}$, reaktör hacmini (L), m, reçine miktarını $(\mathrm{g})$, $\mathrm{q}_{\mathrm{e}}$, iyon değiştirici reçinenin denge anındaki amonyum değişim kapasitesini ve $q_{t}$ ise iyon değiştirici reçinenin t zamanındaki amonyum değişim kapasitesini ifade etmektedir. 


\section{Araştırma Sonuçları ve Tartışma}

\subsection{Başlangıç pH'ının Etkisi}

Çözeltinin $\mathrm{pH}$ değerine bağlı olarak toplam amonyak, amonyum iyonu ve serbest amonyak olmak üzere iki formdan oluşur. $\mathrm{Bu}$ nedenle çözelti $\mathrm{pH}$ '1 amonyumun iyon değiştirme prosesi ile gideriminde önemli bir kontrol parametresidir. Başlangıç pH'ının iyon değişim reçinesi kullanılarak sulu çözeltiden amonyumun giderilmesi üzerindeki etkisini belirlemek için farklı başlangıç $\mathrm{pH}$ (3 - 11 aralığında) değerlerinde deneyler yapılmıştır (Şekil 1). Deneyler de sıcaklık $20^{\circ} \mathrm{C}$, karıştırma hızı $500 \mathrm{rpm}$, reçine dozajı $3 \mathrm{~g} / \mathrm{L}$, başlangıç amonyum konsantrasyonu $30 \mathrm{mg} / \mathrm{L}$ 'dir.
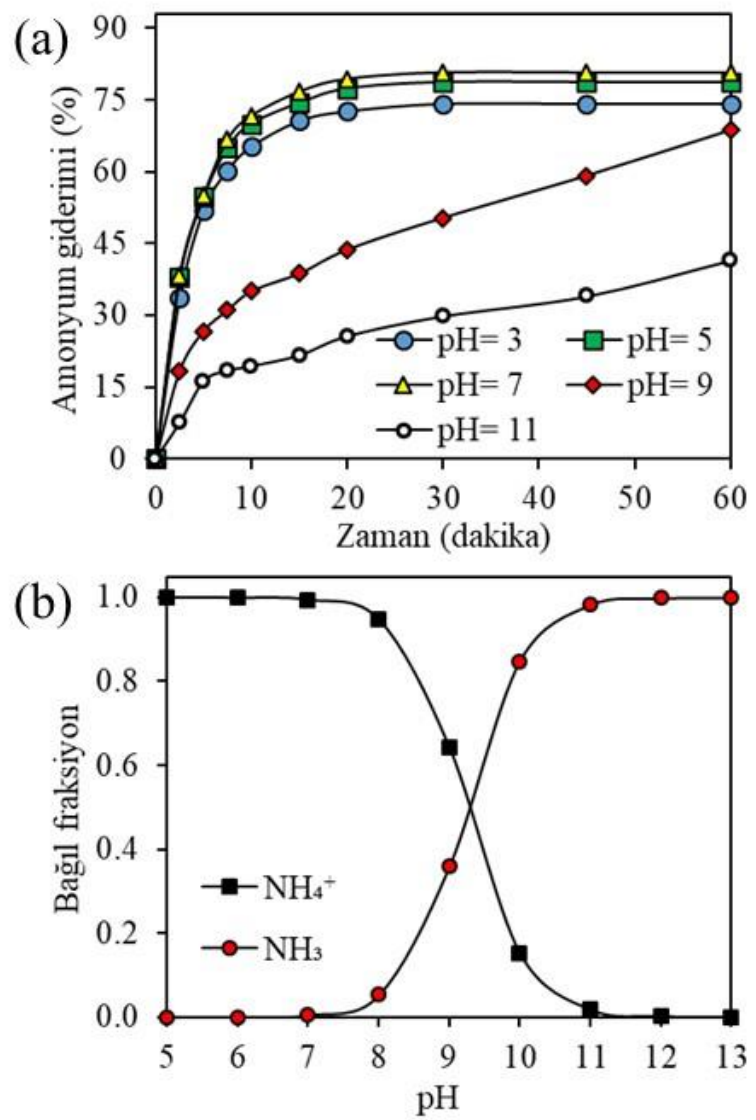

Şekil 1. (a) Başlangıç pH değerinin amonyum giderimine etkisi, (b) $\mathrm{pH}$ değerine bağll olarak amonyum amonyak dengesi (Deneysel şartlar: Karıştırma hızl $=500 \mathrm{rpm}, C_{0}=30 \mathrm{mg} / \mathrm{L}$, Reçine dozajl $=3 \mathrm{~g} / \mathrm{L}, \mathrm{T}=20^{\circ} \mathrm{C}$ )

Şekil 1 (a) başlangıç pH değerinin amonyumun giderimi üzerinde önemli olduğunu göstermiştir. Maksimum giderim verimi $\mathrm{pH}$ 7'de elde edilmiştir. $\mathrm{pH}$ 7'den daha küçük değerlerde amonyum gideriminin azalması $\mathrm{pH}$ ayarlamada kullanılan $\mathrm{HCl}$ ile ilave edilen $\mathrm{H}^{+}$iyonu ile $\mathrm{NH}_{4}{ }^{+}$iyonu arasındaki rekabete bağlanabilir. $\mathrm{pH}$ 7'den büyük değerlerde ise amonyumun gideriminin azalması çözelti pH değerine bağlı olarak Şekil 1 (b) de verilen amonyum iyonu ve serbest amonyak arasında ki bağıl fraksiyon ile açıklanabilir. Özellikle pH 11 değerinde çözeltide ki toplam amonyağın tamamı serbest amonyak formunda olduğundan amonyum giderimi gözlenmemesi gerekir ancak ilave edilen reçine çözelti pH değerini zamanla düşürdüğünden dolayı yüksek $\mathrm{pH}$ değerlerinde amonyum giderimi artmıştır. Başlangıç pH değerleri 9 ve 11 için 60 dakika sonunda $\mathrm{pH}$ değerleri sırasıyla 7.4 ve 10.3 'tür. Ayrıca pH 11 değerinde reçine ilave edilmeden yaklaşık \%7 amonyak giderimi (karıştırma etkisi altında amonyağın sıyrılması ile) tespit edilmiştir. Amonyum giderim hızları göz önüne alındı̆̆ında optimum başlangıç pH değeri 7 seçilmiştir.

\subsection{Karıştırma Hızının Etkisi}

Kesikli işletilen tam karışımlı reaktörlerde yapılan iyon değiştirme işleminde karıştırma hızı önemli bir faktördür. Karıştırma hızının etkisini belirlemek amacıyla reçine dozajı 3 $\mathrm{g} / \mathrm{L}$, sıcaklık $20^{\circ} \mathrm{C}$, başlangıç pH'ı 7 ve başlangıç amonyum konsantrasyonu $30 \mathrm{mg} / \mathrm{L}$ 'de sabit tutularak 200 - $500 \mathrm{rpm}$ arasındaki farklı karıştırma hızlarında deneyler yapılmıştır. Elde edilen sonuçlar Şekil 2'de verilmiştir.
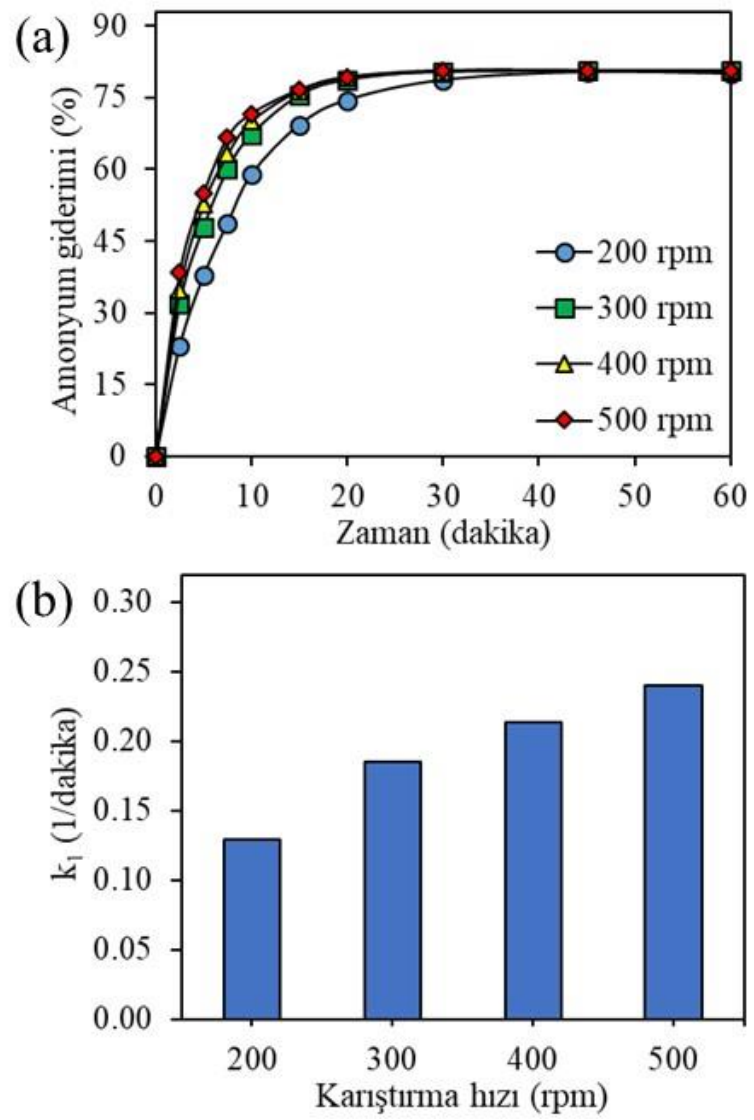

Şekil 2. (a) Karıştırma hızının amonyum giderimine etkisi, (b) yalancı birince derece hı sabiti değerleri (Deneysel şartlar: $C_{0}=30 \mathrm{mg} / \mathrm{L}$, Başlang $\iota c ̧ p H=7$, Reçine dozajl $=3 \mathrm{~g} / \mathrm{L}, \mathrm{T}=20^{\circ} \mathrm{C}$ )

Şekil 2 (a) karıştırma hızındaki artışın, amonyum giderim hızı üzerinde olumlu bir etkisi olduğunu göstermektedir. Karıştırma hızının artışıyla reçine ile amonyum iyonlarının daha iyi etkileşimi sağlanmıştır ve amonyum giderim hızları bakımında en yüksek giderim hızı 500 rpm'de elde edilmiştir. $\mathrm{Bu}$ durum karıştırma hızının arttırılması ile sıvı film kalınlığı azalmasına bağlanabilir (Korkmaz ve ark., 2016; Bingul ve ark., 2016). Dolayısıyla amonyum iyonlarının reçine yüzeyine transferi hızlanır. Şekil 2 (a) incelendiğinde 10 dakika sonunda 200, 300, 400 ve $500 \mathrm{rpm}$ 'de sirasiyla $\% 59.0, \% 67.3, \% 70.2$ ve \%71.7 amonyum giderimi elde edilmiştir. Ayrıca tüm karıştırma hızlarında 45 dakika dan sonra amonyum giderimlerinin karıştırma hızından çok fazla etkilenmediği sonucuna varılabilir. Kinetik hesaplamalardan yalancı birinci derece kinetik modele uyduğu belirlenmiştir ve elde edilen sonuçlar Şekil 2 (b)'de verilmiştir. Karıştırma hızının artışı ile reaksiyon hız sabiti değeri de artmıştır. Yalancı birinci derece reaksiyon hız sabiti 
değeri artan karıştırma hızı ile artarak 200, 300, 400 ve 500 rpm için sırasıyla $0.1287,0.1856,0.2134$ ve 0.2400 dakika $^{-1}$ olarak belirlenmiştir. $\mathrm{Bu}$ nedenle, $500 \mathrm{rpm}$ karıştırma hızı aşağıdaki deneyler için optimum parametre olarak seçilmiştir.

\subsection{Reçine Dozajının Etkisi}

Ekonomik faktör göz önüne alındığında daha az reçine kullanılarak maksimum amonyum giderimi sağlamak büyük önem taşımaktadır. Düşük miktarda reçine ilavesi ile iyon değişim bölgelerinin amonyum iyonlarına tam olarak maruz bırakılması, bir reçinenin maksimum iyon değiştirme kapasitesine ulaşmasını kolaylaştırır (Liu ve ark., 2018). Bu nedenle reçine dozajının amonyum giderim verimine olan etkisini belirlemek için $1 \mathrm{~g} / \mathrm{L}$ 'den $6 \mathrm{~g} / \mathrm{L}$ 'ye kadar değişen reçine dozajlarında deneyler yapılmıştır ve sonuçlar Şekil 3'te gösterilmiştir. $\mathrm{Bu}$ deneylerde başlangıç amonyum konsantrasyonu $30 \mathrm{mg} / \mathrm{L}$, başlangıç pH'1 7, karıştırma hızı 500 rpm ve sicaklik $20^{\circ} \mathrm{C}$ 'de sabit tutulmuştur.

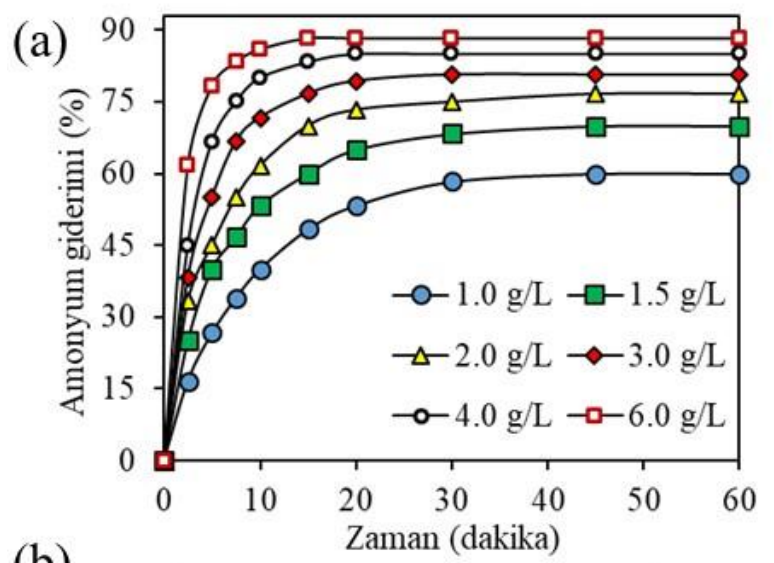

(b)

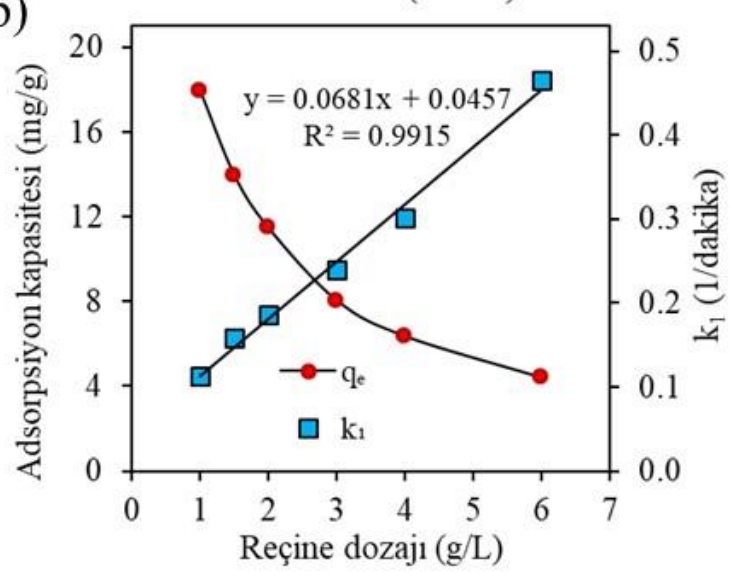

Şekil 3. (a) Reçine dozajının amonyum giderimine etkisi, (b) Adsorpsiyon kapasitesi ve yalancı birince derece reaksiyon hiz sabiti değerleri (Deneysel şartlar: Karıştırma hızl $=500 \mathrm{rpm}$, $C_{0}=30 \mathrm{mg} / \mathrm{L}$, Başlangıç $\mathrm{pH}=7, \mathrm{~T}=20^{\circ} \mathrm{C}$ )

Şekil 3 (a) incelendiğinde reçine dozajının 1 g/L'den 6 g/L'ye artışı ile amonyum giderimi 60 dakika temas süresi sonunda yaklaşık \%60'dan \%88.3'e kadar artmıştır. İyon değiştirme işlemi reçinenin yüzeyinde meydana geldiğinden reçine dozajının artışı yüzey alanının artmasına ve dolayısıyla amonyum giderim veriminin artmasına neden olmuştur. Ancak Şekil 3 (b)'de reçine dozajının 1 g/L'den 6 g/L'ye artmasıyla amonyum iyon değiştirme kapasitesi $18 \mathrm{mg} / \mathrm{g}$ 'dan $4.4 \mathrm{mg} / \mathrm{g}$ 'a azalmıştır. $\mathrm{Bu}$ durum artan reçine dozajı ile gereğinden fazla iyon değiştirme bölgesinin varlığına atfedilebilir. Ding ve Sartaj (2016) yaptıkları çalışmada Amberlite IR120 H iyon değiştirici e-ISSN: 2148-2683 reçine kullanarak benzer sonuçlar elde etmiştir. $12.5 \mathrm{~g} / \mathrm{L}$ reçine (Amberlite IR120 H) dozajında amonyum iyon değiştirme kapasitesi $23.49 \mathrm{mg} / \mathrm{g}$ iken reçine dozajının $100 \mathrm{~g} / \mathrm{L}$ 'ye arttırılması ile amonyum iyon değiştirme kapasitesi $8.43 \mathrm{mg} / \mathrm{g}$ 'a düştüğünü tespit etmişlerdir. Elde edilen deneysel sonuçlardan yalanc1 birinci derece reaksiyon h1z sabiti değerleri hesaplanmıştır ve Şekil 3 (b)'de verilmiştir. Artan reçine dozajı ile reaksiyon hız sabiti değerleri arasında lineer bir ilişki olduğu bulunmuştur. $1 \mathrm{~g} / \mathrm{L}$ reçine dozajında hız sabiti 0.1133 dakika $^{-1}$ iken $6 \mathrm{~g} / \mathrm{L}$ 'de 0.4664 dakika $^{-1}$ 'dir.

\subsection{Sıcaklığın Etkisi}

Reçine gözenekleri düşük sicaklıklarda büzüşebilir yüksek sicaklıklarda ise büyüyebilir (Korkmaz ve ark., 2016). Bu nedenle reçinenin iyon değiştirme kapasitesi sıcaklıkla değişir. Purolite SSTC60 reçinesinin amonyum iyonu değişim kapasitesi üzerine sıcaklığın $\left(10,20,30\right.$ ve $\left.40^{\circ} \mathrm{C}\right)$ etkisi çalışılmıştır. Deneyler reçine dozajı $3 \mathrm{~g} / \mathrm{L}$, başlangıç $\mathrm{pH}^{\prime}$ ' 7, karıştırma hızı $500 \mathrm{rpm}$ ve başlangıç amonyum konsantrasyonu $30 \mathrm{mg} / \mathrm{L}$ 'de yapılmıştır. Deneysel sonuçlar Şekil 4 'te verilmiştir.
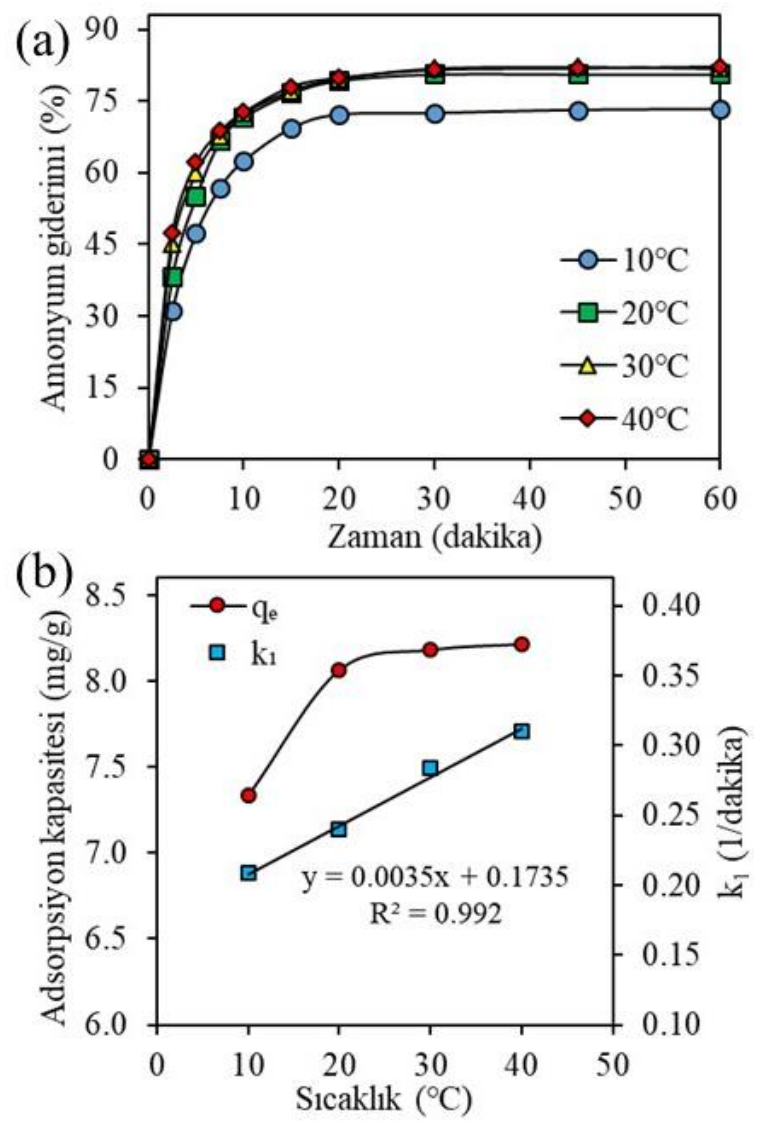

Şekil 4. (a) Sicaklı̆̆ın amonyum adsorpsiyonuna etkisi, (b) Adsorpsiyon kapasitesi ve yalancı birince derece reaksiyon hız sabiti değerleri (Deneysel şartlar: Karıştırma hızl $=500 \mathrm{rpm}$,

$C_{0}=30 \mathrm{mg} / \mathrm{L}$, Başlanglç $\mathrm{pH}=7$, Reçine dozajl $=3 \mathrm{~g} / \mathrm{L}$ )

Şekil 4 (a) incelendiğinde sıcaklığın $10^{\circ} \mathrm{C}$ 'den $20^{\circ} \mathrm{C}$ 'ye artışı amonyum giderim verimi üzerine etkili olduğu görülmüştür. Ancak $20^{\circ} \mathrm{C}$ 'den daha yüksek sıcaklıklarda amonyum giderim verimlerinde ki değişimin çok önemli olmadığ 1 söylenebilir. $10^{\circ} \mathrm{C}$ 'de denge anında \%73.3 amonyum giderim verimi gözlenirken $20^{\circ} \mathrm{C}$ 'de amonyum giderim verimi \%80.7'ye artmıştır. Sıcaklık artışı ile amonyum giderim hızı artmıştır. Bunun nedeni sıcaklık artışı ile gözenek difüzyon hızının artmasına bağlanabilir (Aydin ve ark., 2017). $20^{\circ} \mathrm{C}, 30^{\circ} \mathrm{C}$ 
ve $40^{\circ} \mathrm{C}$ 'de amonyum giderimleri incelendiğinde 10 dakika'dan sonra amonyum gideriminin küçük farklılıklar ile sınırlı olduğu söylenebilir. Şekil 4 (b)'de denge zamanında ki iyon değiştirme kapasiteleri incelendiğinde $20^{\circ} \mathrm{C}$ 'den yüksek sicaklıklarda iyon değiştirme kapasitesinde çok küçük farklılıklar vardır. Bu nedenlerden dolayı amonyum giderimi için optimum sicaklık $20^{\circ} \mathrm{C}$ seçilmiştir.

\subsection{Başlangıç $\mathrm{NH}_{4}{ }^{+}$Konsantrasyonunun Etkisi}

Başlangıç amonyum konsantrasyonunun etkisini belirlemek amacıyla yapılan deneylerde sıcaklık, başlangıç pH'ı, karıştırma hızı ve reçine dozajı sabit tutularak 15 ila $120 \mathrm{mg} / \mathrm{L}$ arasında değişen amonyum konsantrasyonlarında deneyler yapılmıştır ve elde edilen sonuçlar Şekil 5'te verilmiştir. Deneylerde reçine dozaj1 $3 \mathrm{~g} / \mathrm{L}$, başlangıç pH'sı 7, karıştırma hızı $500 \mathrm{rpm}$ ve sicaklık $20^{\circ} \mathrm{C}$ 'dir.
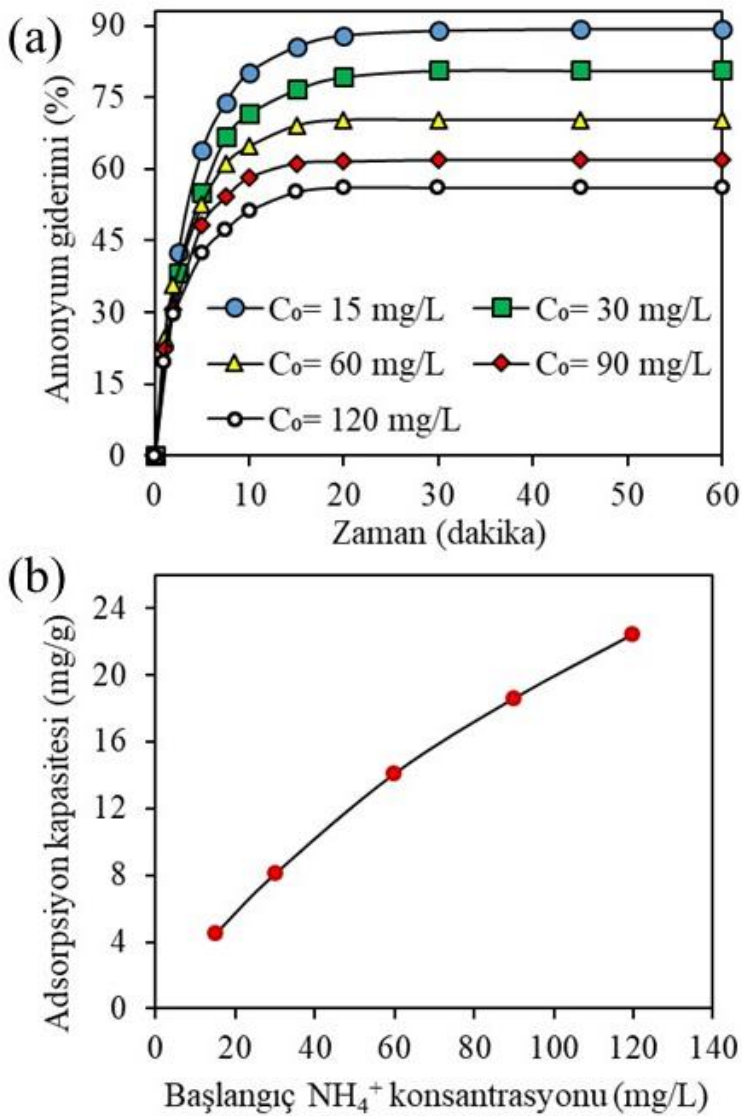

Şekil 5. (a) Başlangıç amonyum konsantrasyonunun amonyum giderimine etkisi, (b) Adsorpsiyon kapasitesi (Deneysel şartlar: Karıştırma hızı $=500 \mathrm{rpm}, \mathrm{T}=20^{\circ} \mathrm{C}$, Başlang $\iota c ̧ p H=7$, Reçine dozajl $=3 \mathrm{~g} / \mathrm{L}$ )

Şekil 5 (a) başlangıç amonyum konsantrasyonunun artışı ile amonyum giderim veriminin azaldığını göstermektedir. Sabit miktardaki reçine yüzeyinde amonyum iyonlarının yer değiştirebileceği alanların miktarı da sabit olduğundan, başlangıç amonyum konsantrasyonunun artması ile giderim verimleri azalır. $15 \mathrm{mg} / \mathrm{L}$ başlangıç amonyum konsantrasyonunda denge anında \%89.3 amonyum giderim sağlanırken $120 \mathrm{mg} / \mathrm{L}$ başlangıç amonyum konsantrasyonunda denge anında \%56.1 amonyum giderimi sağlanmıştır. Ancak amonyum konsantrasyonunun artışı ile iyon değiştirme kapasitesi artmıştır. Kullanılan reçinenin amonyum değişim kapasitesi 15, 30, 60, 90 ve $120 \mathrm{mg} / \mathrm{L}$ başlangıç amonyum konsantrasyonu için sırasıyla $4.47,8.07,14.1,18.6$ ve $22.4 \mathrm{mg} / \mathrm{g}$ 'dir.

e-ISSN: 2148-2683

\section{6. İyon Değiştirme Kinetiği}

Reçineler üzerindeki iyon değişimi, sıvı faz ile katı faz arasındaki bir kütle transfer işlemidir. Bu fenomen, modelleri geliştirmek için veri sağlayacak bir denge ve kinetik hız tarafindan karakterize edilir (Darracq ve ark., 2014). İyon değiştirici reçinenin amonyum değişim hızını, dengede ki ve denge dışı koşullar altında elde edilen iyon değişim kapasitesini tanımlamak için yalancı birinci derece (Lagergren, 1898) ve yalanc1 ikinci dereceden (Blanchard ve ark., 1984) kinetik modeller kullanılmıştır. Yalancı birinci dereceden kinetik model Eşitlik 4 ile yalancı ikinci dereceden kinetik model ise Eşitlik 5 ile gösterilmektedir:

$$
\begin{gathered}
q_{t}=q_{e}\left(1-e^{-k_{1} t}\right) \\
q_{t}=\frac{k_{2} q_{e}^{2} t}{1+k_{2} q_{e} t}
\end{gathered}
$$

burada $\mathrm{k}_{1}$ yalancı birinci dereceden kinetik model için hız sabitini (1/dakika); $\mathrm{k}_{2}$ yalancı ikinci dereceden kinetik model için hı sabitini ( $\mathrm{g} / \mathrm{mg} /$ dakika); $\mathrm{q}_{\mathrm{t}}$ ve $\mathrm{q}_{\mathrm{e}}$ ise sirasıyla $\mathrm{t}$ zamanındaki ve dengede ki amonyum değişim kapasitesini $(\mathrm{mg} / \mathrm{g})$ temsil etmektedir.

$\mathrm{Bu}$ kinetik modellerin doğrusal formlarının kullanılan verilere bağlı olarak hatalı sonuçlara ve dolayısıyla yanlış kararlara neden olduğu ve doğrusal olmayan formlarının, deneysel verilerin uyumu için doğrusal formlarından daha iyi sonuçlar verdiği literatürde belirtilmiştir (Lima ve ark., 2015; Lin ve Wang, 2009; Simonin, 2016). Bu nedenle maksimum (dengede ki) iyon değiştirme kapasitesi ve hız sabiti değerleri doğrusal olmayan yöntem kullanılarak elde edilmiş ve sonuçlar Tablo 2'de verilmiştir. Şekil 6'da farklı başlangıç amonyum konsantrasyonlarının Purolite SSTC60 iyon değiştirici reçine kullanılarak amonyumun giderimi için doğrusal olmayan yalanc1 birinci derece ve yalanci ikinci derece kinetik modellerinin deneysel ve tahmin edilen sonuçlarını göstermektedir. Elde edilen verilerden yalancı birinci derece kinetik model ile yalancı ikinci derece kinetik modelin her ikisi de yüksek $\mathrm{R}^{2}$ değerine sahiptir. Ancak, dengedeki iyon değiştirme kapasiteleri incelendiğinde yalancı birinci derece kinetik model için hesaplanan değerler, deneysel değerler ile daha uyumlu olduğu sonucuna varılabilir. Yalancı ikinci dereceden kinetik model ile elde edilen $\mathrm{q}_{\mathrm{e}}$ değerleri ise deneysel sonuçlardan elde edilen değerlerden her zaman daha yüksektir. Şekil 6 incelendiğinde başlangıç amonyum konsantrasyonun değişimine bağlı olarak 60 dakika sonunda sistemin kararlı halde olduğu görülmektedir. $\mathrm{Bu}$ nedenle yalancı birinci derece kinetik modelin amonyumun Purolite SSTC60 reçinesi ile iyon değişimini daha iyi tanımladığı söylenebilir.

\subsection{Adsorpsiyon İzotermi}

Adsorpsiyon izotermleri adsorbat ve adsorbent arasındaki etkileşimi göstermek için kullanılır (Değermenci ve ark., 2019). Başlangıç amonyum konsantrasyonu ile denge adsorpsiyon kapasitesi arasındaki ilişki, adsorpsiyon izoterm modelleri kullanılarak incelenmiştir. İyon değiştirici reçine ile amonyum arasındaki etkileşimi araştırmak için kesikli deneylerden elde edilen sonuçlar ile adsorpsiyon dengesi çalışmaları yapılmıştır. Yaygın olarak kullanılan Langmuir ve Freundlich izoterm modelleri adsorpsiyon izotermini yorumlamak için kullanılmıştır. 
(a)
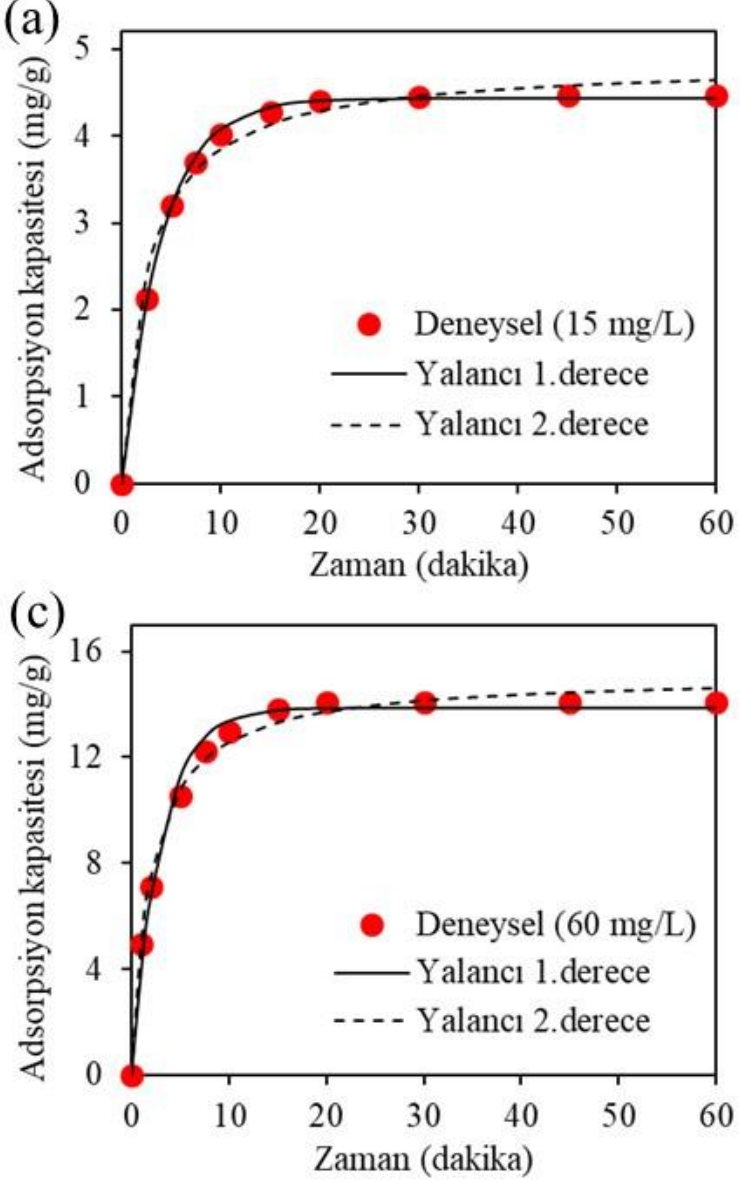

(b)

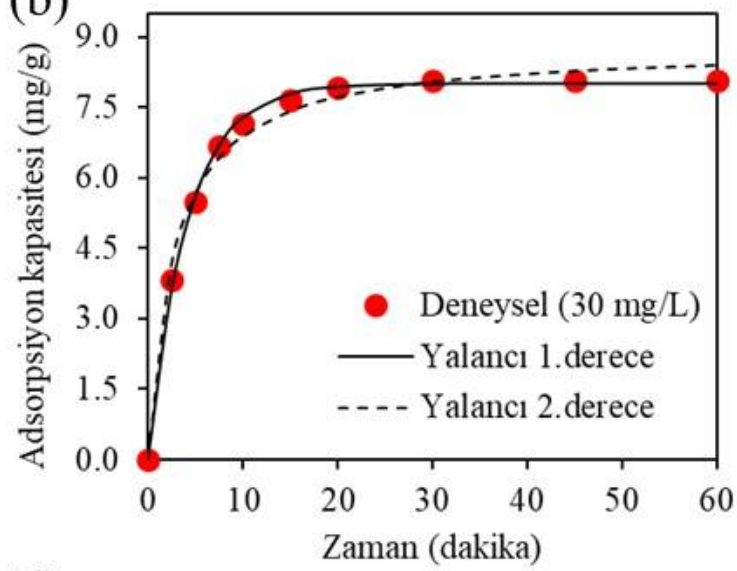

(d)

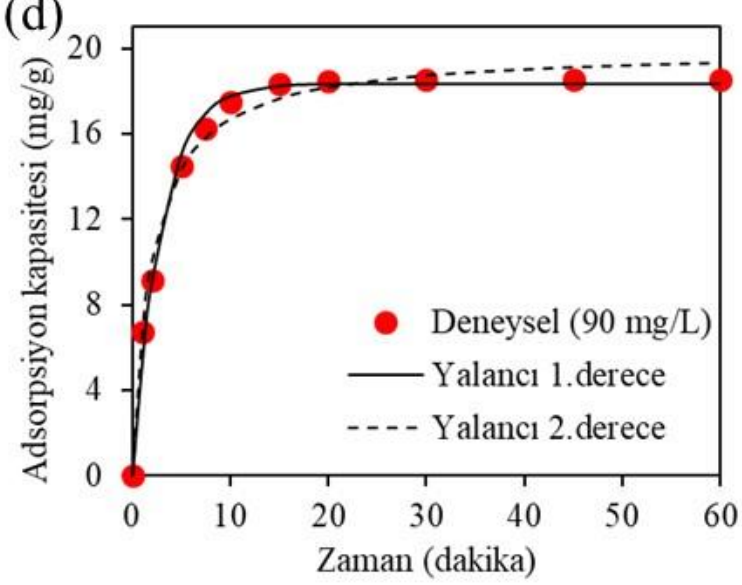

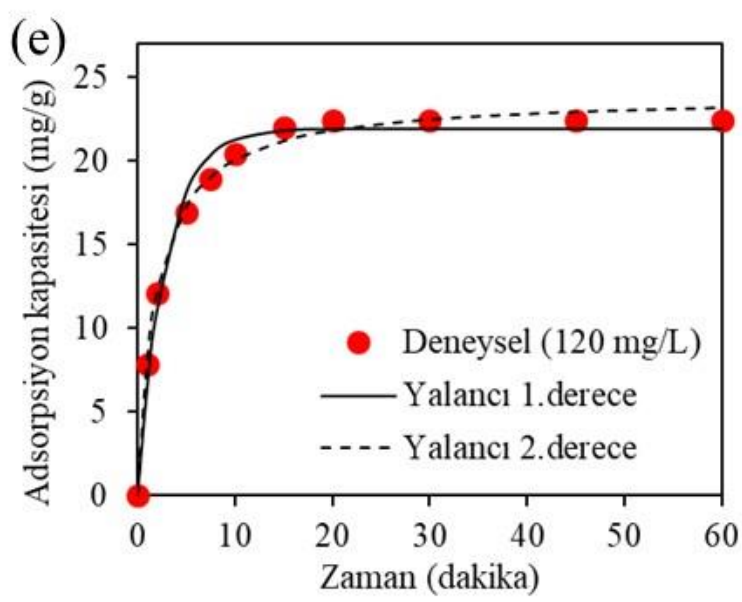

Sekil 6. Farkl başlanglç amonyum konsantrasyonların da (a) $15 \mathrm{mg} / \mathrm{L}$, (b) $30 \mathrm{mg} / \mathrm{L}$, (c) $60 \mathrm{mg} / \mathrm{L}$, (d) $90 \mathrm{mg} / \mathrm{L}$ ve (e) $120 \mathrm{mg} / \mathrm{L}$ lineer olmayan yöntemle hesaplanan yalancı birinci derece ve yalancı ikinci derece reaksiyon kinetikleri (Deneysel şartlar: Karlștırma hızl= $500 \mathrm{rpm}, \mathrm{T}=20^{\circ} \mathrm{C}$, Başlangıç $\mathrm{pH}=7$, Reçine dozajl $=3 \mathrm{~g} / \mathrm{L}$ )

Tablo 2. Yalancı birinci dereceden ve yalancı ikinci dereceden kinetik model sabitleri

\begin{tabular}{|c|c|c|c|c|c|c|c|}
\hline \multirow[b]{2}{*}{$\begin{array}{l}\mathrm{C}_{0} \\
(\mathrm{mg} / \mathrm{L})\end{array}$} & \multirow[b]{2}{*}{$\begin{array}{l}\mathrm{q}_{\mathrm{e}, \text { deney }} \\
(\mathrm{mg} / \mathrm{g})\end{array}$} & \multicolumn{3}{|c|}{ Yalanci birinci derece kinetik } & \multicolumn{3}{|c|}{ Yalancı ikinci derece kinetik } \\
\hline & & $\begin{array}{c}\mathrm{k}_{1} \\
(1 / \text { dakika })\end{array}$ & $\begin{array}{l}\mathrm{q}_{\mathrm{e}, \text { hesap }} \\
(\mathrm{mg} / \mathrm{g})\end{array}$ & $\mathrm{R}^{2}$ & $\begin{array}{c}\mathrm{k}_{2} \\
\text { (g/mg'dakika) }\end{array}$ & $\begin{array}{l}\mathrm{q}_{\mathrm{e}, \text { hesap }} \\
(\mathrm{mg} / \mathrm{g})\end{array}$ & $\mathrm{R}^{2}$ \\
\hline 15 & 4.47 & 0.2516 & 4.43 & 0.9991 & 0.0793 & 4.85 & 0.9904 \\
\hline 30 & 8.07 & 0.2400 & 8.00 & 0.9984 & 0.0412 & 8.79 & 0.9911 \\
\hline 60 & 14.1 & 0.3344 & 13.9 & 0.9899 & 0.0327 & 15.1 & 0.9941 \\
\hline 90 & 18.6 & 0.3457 & 18.3 & 0.9922 & 0.0256 & 20.0 & 0.9919 \\
\hline 120 & 22.4 & 0.3504 & 21.9 & 0.9851 & 0.0216 & 23.9 & 0.9958 \\
\hline
\end{tabular}


Langmuir izoterm modeli adsorpsiyonun homojen adsorbent yüzeyinde meydana geldiğini ve adsorbat molekülleri arasında etkileşim olmadığını varsaymaktadır. Bu modele göre adsorbent üzerinde sadece tek tabakalı adsorpsiyon vardır (Langmiur, 1918; Tran ve ark., 2017). Bu tür tek tabakalı adsorpsiyon işlemi sınırlı sayıda benzer bölgeye sahip adsorbent yüzeyinde gerçekleşir. Langmuir izoterm modelinin doğrusal olmayan formu Eşitlik 6 ile ifade edilir:

$$
q_{e}=\frac{q_{m} K_{L} C_{e}}{1+K_{L} C_{e}}
$$

burada $\mathrm{q}_{\mathrm{m}}(\mathrm{mg} / \mathrm{g})$ ve $\mathrm{K}_{\mathrm{L}}(\mathrm{L} / \mathrm{mg})$ sirasiyla adsorpsiyon kapasitesi ve adsorpsiyon enerjisi (adsorban ve adsorbat arasındaki afinite) ile ilgili Langmuir sabitidir.

Freundlich izoterm modeli, heterojen bir yüzey için denge verilerini ve adsorpsiyon özelliklerini tanımlamak için kullanılan en eski ampirik denklemlerden biridir. Freundlich izoterm modeli adsorpsiyonun farklı adsorpsiyon enerjisine sahip bölgelerde heterojen yüzeyde meydana geldiğini varsayar (Freundlich, 1906; Tran ve ark., 2017). Freundlich izoterm modelinin doğrusal olmayan formu eşitlik 7 ile ifade edilebilir:

$$
q_{e}=K_{F} C_{e}^{n}
$$

burada $K_{F}$ Freundlich sabitini $n$ ise yüzey heterojenliğini veya adsorpsiyon yoğunluğunu ifade etmektedir. Freundlich teorisine göre, adsorpsiyon izotermi $\mathrm{n}=1$ olduğunda doğrusal, $\mathrm{n}<1$ olduğunda uygun ve $n>1$ olduğunda elverişsiz hale gelir.

Langmuir ve Freundlich sabitleri hesaplanmış ve sonuçlar Tablo 3'te gösterilmiştir. Denge konsantrasyonuna karşılık hesaplanan denge adsorpsiyon kapasitelerinin uyumu karşılaştırıldığında, yüksek determinasyon katsayısı $\left(\mathrm{R}^{2}\right)$ amonyumun adsorpsiyonu için Langmiur izorterm modelinden ziyade Freundlich izoterm modelinin daha uygun olduğunu göstermektedir. Bu sonuç, reçine üzerinde amonyum iyonlarının çok katmanlı adsorpsiyon ile karakterize edildiğini ve yüzeylerinin heterojen olduğunu gösterir. Reçinenin tek tabakalı (Langmiur) adsorpsiyon kapasitesi $\left(\mathrm{q}_{\mathrm{m}}\right)$ ise $27.49 \mathrm{mg} / \mathrm{g}$ olarak belirlenmiştir.

Tablo 3. Langmuir ve Freundlich izoterm parametreleri

\begin{tabular}{lll}
\hline İzotermler & Parametreler & Değerler \\
\hline \multirow{3}{*}{ Langmiur } & $\mathrm{q}_{\mathrm{m}}(\mathrm{mg} / \mathrm{g})$ & 27.49 \\
& $\mathrm{~K}_{\mathrm{L}}(\mathrm{L} / \mathrm{mg})$ & 0.068 \\
& $\mathrm{R}^{2}$ & 0.975 \\
\hline \multirow{3}{*}{ Freundlich } & $\mathrm{K}_{\mathrm{F}}\left[(\mathrm{mg} / \mathrm{g}) /(\mathrm{mg} / \mathrm{L})^{\mathrm{n}}\right]$ & 3.699 \\
& $\mathrm{n}$ & 0.456 \\
& $\mathrm{R}^{2}$ & 0.999 \\
\hline
\end{tabular}

\section{Sonuç}

İyon değiştirici reçine (Purolite SSTC60) kullanılarak sulu çözeltilerden amonyum giderimi gerçekleştirilmiştir. İyon değiştirici reçine kullanarak amonyum gideriminde başlangıç $\mathrm{pH}$ değeri, karıştırma hızı, reçine dozajı, başlangıç amonyum konsantrasyonu ve sıcaklığın amonyum giderimi üzerine etkileri sistematik olarak araştırılmıştır. Amonyum giderimi $\mathrm{pH}$ değerine büyük oranda bağlıdır ve en yüksek amonyum giderimi $\mathrm{pH}$ 7'de gerçekleştirilmiştir. Amoynum giderim hızları karıştırma hızı, sıcaklık ve reçine dozajının artması ile artarken başlangıç amonyum konsantrasyonunun artışı ile azalmıştır. $30 \mathrm{mg} / \mathrm{L}$ amonyum konsantrasyonunda reçine dozaj1 $3 \mathrm{~g} / \mathrm{L}$, başlangıç pH'1 7, karıştırma hızı 500 rpm ve sıcaklık $20^{\circ} \mathrm{C}$ için $\% 80.7$ amonyum giderimi elde edilmiştir. Aynı şartlarda reçine dozajının 6 g/L'ye arttırılması ile amonyum giderim verimi de artarak \%88.7 olmuştur. Kinetik modellerin doğrusal formlarının analizinde veri sayılarının yetersizliği nedeniyle hatalı sonuçlara ve dolayısıyla yanlış kararlara neden olduğundan dolayı doğrusal olmayan formları kullanılmış ve yalancı birinci derece kinetik modelin amonyum giderimini daha iyi yansıttığı ortaya koyulmuştur. Adsorpsiyon verilerinin Langmiur izoterm modelinden ziyade Freundlich modeline uyduğu belirlenmiştir.

\section{Teșekkür}

Bu çalışma, Kastamonu Üniversitesi Bilimsel Araştırma Projeleri Koordinasyon Birimi tarafindan "KÜ-BAP01/2017-40" kodlu proje ile desteklenmiştir.

\section{Kaynakça}

Alshameri, A., Ibrahim, A., Assabri, A.M., Lei, X., Wang, H., \& Yan, C. (2014). The investigation into the ammonium removal performance of Yemeni natural zeolite: Modification, ion exchange mechanism, and thermodynamics. Powder Technology, 258, 20-31.

Aşçi, B., Kövenç, E., Arar, Ö., \& Arda, M. (2018). Kinetic, isotherm and thermodynamic investigations of nitrite (NO2) removal from water by anion exchange resins. Global Nest Journal, 20, 368-372.

Awual, M.R., \& Jyo, A. (2011). Assessing of phosphorus removal by polymeric anion exchangers. Desalination, 281, 111-117.

Aydin, Ö., Özmetin, C., Korkmaz, M., \& Fil, B.A. (2017). A semiempirical kinetic model for removal of iron $(\mathrm{Fe} 3+)$ from saturated boric acid solution by ion exchange using amberlite IR-120 resin. Particulate Science and Technology, 35, 505-511.

Bahmani, M., Dashtian, K., Mowla, D., Esmaeilzadeh, F., \& Ghaedi, M. (2020). UiO-66(Ti)-Fe3O4-WO3 photocatalyst for efficient ammonia degradation from wastewater into continuous flow-loop thin film slurry flat-plate photoreactor. Journal Hazardous Materials, 393, 122360.

Bashir, M.J.K., Aziz, H.A., Yusoff, M.S., \& Adlan, M.N. (2010). Application of response surface methodology (RSM) for optimization of ammoniacal nitrogen removal from semiaerobic landfill leachate using ion exchange resin. Desalination, 254, 154-161.

Bermejo, M.D., Cantero, F., \& Cocero, M.J. (2008). Supercritical water oxidation of feeds with high ammonia concentrations. Pilot plant experimental results and modeling. Chemical Engineering Journal, 137, 542-549.

Bingul, Z., Gurbuz, H., Aslan, A., \& Ercisli, S. (2016). Biosorption of zinc(II) from aqueous solutions by nonliving lichen biomass of xanthoria parietina (L.) Th. Fr. Environmental Engineering and Management Journal, 15(12).

Blanchard, G., Maunaye, M., \& Martin, G. (1984). Removal of heavy metals from waters by means of natural zeolites. Water Research, 18, 1501-1507.

Bonmatí, A., \& Flotats, X. (2003). Air stripping of ammonia from pig slurry: Characterisation and feasibility as a pre- or post-treatment to mesophilic anaerobic digestion. Waste Management, 23, 261-272. 
Caetano, M., Valderrama, C., Farran, A., \& Cortina, J.L. (2009). Phenol removal from aqueous solution by adsorption and ion exchange mechanisms onto polymeric resins. Journal of Colloid and Interface Science, 338, 402-409.

Carrera, J., Baeza, J.A., Vicent, T., \& Lafuente, J. (2003). Biological nitrogen removal of high-strength ammonium industrial wastewater with two-sludge system. Water Research, 37, 4211-4221.

Cheng, P., Chen, D., Liu, H., Zou, X., Wu, Z., Xie, J., Qing, C., Kong, D., \& Chen, T. (2018). Synergetic effects of anhydrite and brucite-periclase materials on phosphate removal from aqueous solution. Journal of Molecular Liquids, 254, 145153.

Chung, S., Chung, J., \& Chung, C. (2020). Enhanced electrochemical oxidation process with hydrogen peroxide pretreatment for removal of high strength ammonia from semiconductor wastewater. Journal of Water Process Engineering, 37, 101425.

Darracq, G., Baron, J., \& Joyeux, M. (2014). Kinetic and isotherm studies on perchlorate sorption by ion-exchange resins in drinking water treatment. Journal of Water Process Engineering, 3, 123-131.

Değermenci, G.D., Değermenci, N., Ayvaoğlu, V., Durmaz, E., Çakır, D., \& Akan, E. (2019). Adsorption of reactive dyes on lignocellulosic waste; characterization, equilibrium, kinetic and thermodynamic studies. Journal of Cleaner Production, 225, 1220-1229.

Değermenci, N., Ata, O.N., \& Yildiz, E. (2012). Ammonia removal by air stripping in a semi-batch jet loop reactor. Journal of Industrial and Engineering Chemistry, 18, 399404.

Ding, Y., \& Sartaj, M. (2016). Optimization of ammonia removal by ion-exchange resin using response surface methodology. International Journal of Environmental Science and Technology, 13, 985-994.

Freundlich, H. (1907). Über die adsorption in lösungen. Zeitschrift für physikalische Chemie, 57, 385-470.

Hazwani-Oslan, S.N., Tan, J.S., Saad, M.Z., Halim, M., \& Ariff, A.B. (2017). Improved cultivation of gdhA derivative Pasteurella multocida B:2 for high density of viable cells through in situ ammonium removal using cation-exchange resin for use as animal vaccine. Process Biochemistry, 56, $1-7$.

Jorgensen, T.C., \& Weatherley, L.R. (2006). Continuous removal of ammonium ion by ion exchange in the presence of organic compounds in packed columns. Journal of Chemical Technology and Biotechnology, 81, 1151-1158.

Kalaruban, M., Loganathan, P., Shim, W.G., Kandasamy, J., Naidu, G., Nguyen, T.V., \& Vigneswaran, S. (2016). Removing nitrate from water using iron-modified Dowex $21 \mathrm{~K}$ XLT ion exchange resin: Batch and fluidised-bed adsorption studies. Separation and Purification Technology, 158, 62-70.

Korkmaz, M., Özmetin, C., \& Fil, B.A. (2016). Modelling of Boron Removal from Solutions Using Purolite S 108 in a Batch Reactor. Clean - Soil Air Water, 44, 949-958.

Körner, S., Das, S.K., Veenstra, S., \& Vermaat, J.E. (2001). The effect of $\mathrm{pH}$ variation at the ammonium/ammonia equilibrium in wastewater and its toxicity to Lemna gibba. Aquatic Botany, 71, 71-78.

Lagergren, S.K. (1898). About the theory of so-called adsorption of soluble substances. Kungliga Svenska Vetenskaps akademiens Handlingar, 24, 1-39.
Langmuir, I. (1918). The adsorption of gases on plane surfaces of glass, mica and platinum. Journal of the American Chemical society, 40, 1361-1403.

Lima, É. C., Adebayo, M. A., \& Machado, F. M. (2015). Kinetic and equilibrium models of adsorption. In Carbon nanomaterials as adsorbents for environmental and biological applications (pp. 33-69). Springer, Cham.

Lin, J., \& Wang, L. (2009). Comparison between linear and nonlinear forms of pseudo-first-order and pseudo-second-order adsorption kinetic models for the removal of methylene blue by activated carbon. Frontiers of Environmental Science and Engineering, 3, 320-324.

Lin, L.C., \& Juang, R.S. (2007). Ion-exchange kinetics of Cu(II) and $\mathrm{Zn}(\mathrm{II})$ from aqueous solutions with two chelating resins. Chemical Engineering Journal, 132, 205-213.

Liu, R., Chi, L., Wang, X., Sui, Y., Wang, Y., \& Arandiyan, H. (2018). Review of metal (hydr)oxide and other adsorptive materials for phosphate removal from water. Journal of Environmental Chemical Engineering, 6, 5269-5286.

Mondor, M., Masse, L., Ippersiel, D., Lamarche, F., \& Massé, D.I. (2008). Use of electrodialysis and reverse osmosis for the recovery and concentration of ammonia from swine manure. Bioresource Technology, 99, 7363-7368.

Nur, T., Shim, W.G., Loganathan, P., Vigneswaran, S., \& Kandasamy, J. (2015). Nitrate removal using Purolite A520E ion exchange resin: batch and fixed-bed column adsorption modelling. International Journal of Environmental Science and Technology, 12, 1311-1320.

Paul Chen, J., Chua, M.L., \& Zhang, B. (2002). Effects of competitive ions, humic acid, and $\mathrm{pH}$ on removal of ammonium and phosphorous from the synthetic industrial effluent by ion exchange resins. Waste Management, 22, 711-719.

Saltali, K., Sari, A., \& Aydin, M. (2007). Removal of ammonium ion from aqueous solution by natural Turkish (Y1ldizeli) zeolite for environmental quality. Journal Hazardous Materials, 141, 258-263.

Simonin, J.P. (2016). On the comparison of pseudo-first order and pseudo-second order rate laws in the modeling of adsorption kinetics. Chemical Engineering Journal, 300, 254-263.

Taşdemir, A., Cengiz, İ., Yildiz, E., \& Bayhan, Y.K. (2020). Investigation of ammonia stripping with a hydrodynamic cavitation reactor. Ultrasonics Sonochemistry, 60, 104741.

Tran, H.N., You, S.J., Hosseini-Bandegharaei, A., \& Chao, H.P. (2017). Mistakes and inconsistencies regarding adsorption of contaminants from aqueous solutions: a critical review. Water Research, 120, 88-116.

Uludag-Demirer, S., Demirer, G.N., \& Chen, S. (2005). Ammonia removal from anaerobically digested dairy manure by struvite precipitation. Process Biochemistry, 40, 3667-3674.

Víctor-Ortega, M.D., Ochando-Pulido, J.M., \& Martínez-Ferez, A. (2016). Thermodynamic and kinetic studies on iron removal by means of a novel strong-acid cation exchange resin for olive mill effluent reclamation. Ecological Engineering, 86, 53-59.

Wen, Z., Huang, K., Niu, Y., Yao, Y., Wang, S., Cao, Z., \& Zhong, H. (2019). Kinetic study of ultrasonic-assisted uranium adsorption by anion exchange resin. Colloids and Surfaces A: Physicochemical and Engineering Aspects, 585, 124021. 